ORIGINAL

ISSN 0103-5150

Fisioter. Mov., Curitiba, v. 33, e003368, 2020

DOI: http://dx.doi.org/10.1590/1980-5918.032.A067

Licensed under a Creative Commons attribution

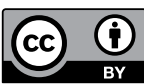

\title{
Mobility and clinical outcome of patients admitted to an intensive care unit
}

\author{
Mobilidade e desfecho clínico de pacientes admitidos em unidade \\ de terapia intensiva
}

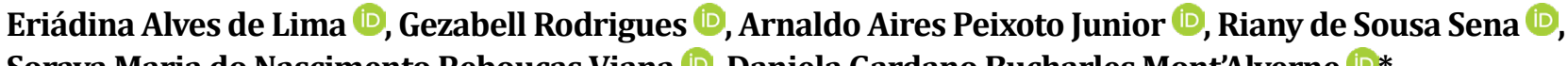
Soraya Maria do Nascimento Rebouças Viana (D), Daniela Gardano Bucharles Mont’Alverne (D*

Universidade Federal do Ceará (UFC), Fortaleza, CE, Brazil

\begin{abstract}
Introduction: The hospital environment exacerbates the effects of immobility due to several exposure factors, and the functional assessment of individuals using reliable instruments is vital. Objective: To determine the relationship between functional mobility and the clinical outcome of patients admitted to an intensive care unit. Method: This is a prospective quantitative longitudinal study, approved by the institutional research ethics committee, carried out in the intensive care unit of a University Hospital. Clinical data and the Acute Physiology and Chronic Health Evaluation (APACHE II) score were collected 24 hours after admission. The Perne Score was used to analyze patient mobility. Results: 33 patients participated, $63 \%$ female. With respect to mobility and transfers, $69.7 \%$ required total assistance from the supine to the sitting position and $70 \%$ to maintain balance, $9.1 \%$ needed minimum assistance from sitting to standing, and $100 \%$ total assistance for walking and endurance exercises. The main barriers to mobility were invasive ventilation (60\%), assistive devices and intravenous infusion (100\%). The following Perne Score domains
\end{abstract}

*EAL: Master's Student, e-mail: eriadna12@hotmail.com

GR: Master's Student, e-mail: abellzge@hotmail.com

AAPJ: PhD, e-mail: arnaldoapj@gmail.com

RSS: PhD, e-mail: rianysena@yahoo.com.br

SMNRV: PhD, e-mail: soraya.viana@bol.com.br

DGBMA: PhD, e-mail: daniela.gardano@hotmail.com 
were significantly associated with the outcome: mental status $(p=0.040)$, barriers to mobility $(p=0.016)$, strength $(p=0.010)$, mobility in bed $(p=0.024)$ and the total Perme Score $(p=0.002)$. There were also significant associations between invasive ventilation and low Perme Scores $(p=0.000)$, and the Richmond Agitation-Sedation Scale (RASS) ( -5 and -4$)$ and death in $66.7 \%$ of patients $(\mathrm{p}=0.011$ ). The Perme Score and RASS $(\mathrm{R}=0.745)$ were moderately correlated and APACHE II and Perme Score inversely moderately correlated $(\mathrm{R}=-0.526)$. Conclusion: Mobility assessed by the Perme Score was related to the clinical outcome and strongly associated with sedation level and patient severity.

Keywords: Mortality. Early Mobilization. Physical Therapy Modalities. Intensive Care. Scales.

\section{Resumo}

Introdução: $O$ ambiente hospitalar potencializa os prejuízos da imobilidade por diversos fatores de exposição, sendo imprescindível a avaliação funcional do indivíduo por meio de instrumentos fidedignos. Objetivo: Verificar a relação entre mobilidade funcional e desfecho clínico de pacientes admitidos em uma unidade de terapia intensiva. Método: Estudo longitudinal prospectivo e quantitativo, aprovado pelo comitê de ética em pesquisa, realizado na unidade de terapia intensiva de um Hospital Universitário. Após 24h da admissão foram coletados dados clínicos e o escore The Acute Physiology and Chronic Health Evaluation (APACHE II). Para análise da mobilidade dos pacientes utilizou-se o Escore Perme. Resultados: Participaram 33 pacientes, 63\% do sexo feminino. Relativo a mobilidade e transferências, 69,7\% necessitavam de assistência total de supino para sentado e 70\% para manter equilíbrio, 9,1\% mínima assistência de sentado para em pé, 100\% assistência total para marcha e endurance. As principais barreiras à mobilidade, foram ventilação invasiva (60\%), dispositivos e infusão endovenosa (100\%). Associando os domínios do Escore Perme com desfecho, houve significância para estado mental $(p=0,040)$,barreiras a mobilidade $(p=0,016)$, força $(p=0,010)$, mobilidade no leito $(p=0,024) e$ pontuação do Escore Perme $(p=0,002)$. Associações significativas entre ventilação invasiva e baixas pontuações no Escore Perme ( $p=0,000)$, associação entre Richmond Agitation-Sedation Scale (RASS) (-5 e -4) com óbito em $66,7 \%$ dos pacientes ( $p=0,011)$.Correlação positiva moderada entre o Escore Perme e RASS $(R=0,745)$ e inversa moderada entre APACHE II e Escore Perme ( $R=-0,526)$. Conclusão: A mobilidade avaliada pelo Escore Perme apresentou relação com o desfecho clínico, e boa associação com o nível de sedação e gravidade dos pacientes.

Palavras-chave: Mortalidade. Deambulação Precoce. Modalidades de Fisioterapia. Cuidados Intensivos. Escalas.

\section{Introduction}

Functional independence is the capacity of individuals to efficiently execute the essential activities of their daily routine [1]. However, a critical health status and the need for hospitalization, especially in intensive care, may affect functionality, compromising the patient's physical fitness and leading to muscle deficits, proteolysis and biomechanical disorders [2,3].

Admission to an intensive care unit (ICU) has been described as an important event related to numerous functional alterations. This is due to the patient's exposure to factors such as prolonged medication use, invasive mechanical ventilation (IVM) and extended hospitalization [4-6]. Functional decline can also predispose individuals to sarcopenia and contribute significantly to increased mortality in intensive care [7].

The body is directly affected by immobility or prolonged bed rest. This situation becomes even more serious in a hospital setting, where patients are submitted to mechanical ventilation, pharmacological agents and nutritional restrictions that contribute to a loss of muscle strength and motor coordination. In this respect, the individual's emotional state is also affected, such as the inability to independently execute the activities of daily living and self-care, where many dysfunctions can persist for up to five years after hospital discharge [8-11]. 
As such, early functional assessment using reliable instruments that enable a more accurate investigation of the individual's condition is essential in finding possible changes and evaluating the efficiency of interventions $[12,13]$. The functional independence measure (FIM) and the Barthel Index are good scales to quantify the functional status of individuals before ICU admission. However, they are not specific to intensive care units, where there is a lack of instruments capable of assessing the patient mobility $[14,15]$.

Among the assessment instruments is the Perme Score, a scale recently validated in Brazil and capable of assessing critical patient mobility, especially considering the potential barriers and limitations they may be exposed to in the ICU, such as mechanical ventilation and drug infusion catheters, among others $[16,17]$.

The International Classification of Functionality Disability and Health (ICF) considers factors that have a direct influence on functionality, such as muscle strength, environmental factors and mobility. A systematic review was conducted to determine the reliability of scales that assess the functionality of critically ill patients found that the Perme Score was the best instrument to that end [18].

Literature studies show a growing interest in biomechanical alterations, especially after patients have been bedridden for long periods. However, studies that carry out an adequate early investigation of patient mobility after ICU admission remain scarce, given that the most widely used instruments do not allow such specificity. This justifies the need to conduct the present study, since it may shed light on why these individuals are being admitted to ICUs and whether there is a relationship between mobility status and their clinical outcome.

Thus, the aim of this study was to determine if there is a correlation between the functional mobility and clinical outcome of patients admitted to an ICU.

\section{Method}

This is a prospective quantitative longitudinal study conducted in a university hospital in Fortaleza Brazil between March and May 2017. The study was approved by the institutional research ethics committee and all the legal guardians provided written informed consent (Protocol no. 2.217.064).

The ICU where the study was held has 8 beds and admits patients from the different hospital wards, as well as clinical and surgical patients with chronic and acute diseases registered at admission centers. Patients admitted to the ICU, aged 18 years and older, hospitalized for 24 hours or longer, were eligible. The eligibility criteria were used to establish the inclusion and exclusion criteria, where patients who were prescribed physical therapy, irrespective of sex, were included.

Excluded were patients with multiple amputations and previously compromised mobility, postural transfers, demyelinating and/or neurological diseases such as stroke, traumatic brain or spinal cord injury, cerebral palsy or neurological repercussions, readmitted patients and those whose medical records lacked the necessary information for complete data collection.

A chart was created to document clinical data during patient hospitalization, based on information obtained from the medical records, and to calculate the The Acute Physiology and Chronic Health Evaluation (APACHE II) score. Data were collected by the principal researcher $24 \mathrm{~h}$ after patient admission to the ICU and monitored until the final outcome, discharge or death.

Patient mobility was analyzed using the Perme Score, a scale recently validated in Brazil, able to measure the mobility of patients hospitalized in an intensive care unit $[15,16]$. Among other factors, the scale considers the mental status, strength, mobility, transfers and barriers that may reflect on patient mobility, and is divided into 15 items, grouped into 7 categories, with scores varying from 0 to 32 points, where the closer to 32 the better the mobility of the individual assessed [15].

With respect to the depth of sedation, patients were assessed using the Richmond Agitation Sedation Scale (RASS), whose scores range from +4 (Agitated) to -5 (Comatose) [19].

The data were analyzed using descriptive and inferential statistics and the Statistical Package for the Social Sciences (SPSS) program, version 20.0, considering a 5\% significance level $(\mathrm{p}<0.05)$. Fisher's Exact test, the Mann-Whitney U test for independent samples and Pearson's correlation were applied.

\section{Results}

A total of 66 patients were admitted during the collection period and 61 deemed eligible to participate in the study. A total of 24 patients were excluded, leaving a sample of 33 individuals. Of the patients studied, $63.6 \%$ were women, with an average age of 
$56.9 \pm 18.0$ years, median ICU hospitalization of 9 days and $60.6 \%$ of the sample required invasive ventilatory support (Table 1).

The severity score measured by APACHE II obtained a median of 15 points, and the sedation level assessed by RASS showed that $54.5 \%$ of the patients received mild sedation ( -1 and 0 ). With respect to the underlying disease, digestive $(24.2 \%)$ and pulmonary causes $(21.2 \%)$ predominated. In regard to clinical outcome, $36.4 \%$ of the patients died (Table 1 ).

Table 1 - Clinical characteristics of the sample. Fortaleza, Brazil, $2017(n=33)$

\begin{tabular}{lc}
\hline \multicolumn{1}{c}{ Variables } & $\mathbf{n}(\%)$ \\
\hline Sex & \\
Female & $21(63.6)$ \\
Age (years) ${ }^{+}$ & $56.94 \pm 18.04$ \\
Etiology of the underlying disease & \\
Digestive & \\
Pulmonary & $8(24.2)$ \\
Hepatic & $7(21.2)$ \\
Hematological & $6(18.2)$ \\
Renal & $4(12.1)$ \\
Cardiological & $4(12.1)$ \\
Vascular & $3(9.1)$ \\
Surgery & $1(3.0)$ \\
Yes & \\
Vasoactive drugs & $9(27.3)$ \\
Yes & \\
MV & $18(54.5)$ \\
Yes & \\
Days on IVM & $20(60.6)$ \\
RASS & $3.35 \pm 4.51$ \\
-5 and -4 & \\
-3 and -2 & $12(36.4)$ \\
-1 and 0 & $3(9.10)$ \\
Outcome & $18(54.5)$ \\
Death & \\
APACHE II * & \\
Time in the ICU* & $12(36.40)$ \\
\hline & $15(7-73)$ \\
\hline & $9(1-60)$ \\
\hline A & \\
\hline
\end{tabular}

Note: $n$ : Absolute frequency; \%: Relative frequency; ${ }^{+}$variable expressed as mean \pm standard deviation; ${ }^{*}$ variables expressed as median (minimum-maximum); RASS: Richmond Agitation-Sedation Scale; APACHE II: Acute Physiology and Chronic Health Evaluation Classification System II; ICU: Intensive care unit. Source: Research data, 2017.

Investigation of the Perme Score by domains found that the main barriers to mobility were the need for ventilatory support (60.6\%), use of assistive devices and the need for endovenous infusion (100\%). With respect to mobility and bed transfers, $69.7 \%$ of the individuals required total assistance to transfer from the supine to the sitting position and $72.7 \%$ to maintain static balance in this position. In transfer from the sitting to standing position and static balance, only $9.1 \%$ of patients were able to execute this with minimum assistance or only supervision. For gait and endurance, $100 \%$ of patients needed total assistance or were incapable of excuting these tasks.

When Perme Score domains were associated with the patients' clinical outcome, there was statistical significance for mental status $(\mathrm{p}=0.040)$, potential barriers to mobility $(\mathrm{p}=0.016)$, functional strength $(p=0.010)$ and mobility in bed $(p=0.024)$. The same occurred when the overall Perme Score was associated with the patients' clinical outcome $(\mathrm{p}=0.002)$ (Table 2).

Table 2 - Association between the Perme Score domains and patients' clinical outcome. Fortaleza, Brazil, $2017(n=33)$

\begin{tabular}{lccc}
\hline \multicolumn{1}{c}{ Variables } & Death & Discharged & p \\
Mental Status & $0(0-3)$ & $3(0-3)$ & $0.040^{\star}$ \\
$\begin{array}{l}\text { Potential } \\
\text { Barriers }\end{array}$ & $0(0-2)$ & $1(0-3)$ & $0.016^{\star}$ \\
$\begin{array}{l}\text { Functional } \\
\text { Strength }\end{array}$ & $0(0-2)$ & $2(0-4)$ & $0.010^{\star}$ \\
Mobility in Bed & $0(0-0)$ & $0(0-6)$ & $0.024^{*}$ \\
Transfers & $0(0-0)$ & $0(0-7)$ & 0.385 \\
Gait & $0(0-0)$ & $0(0-0)$ & 1.000 \\
Endurance & $0(0-0)$ & $0(0-0)$ & 1.000 \\
Perme Score & $0(0-10)$ & $10(0-23)$ & $0.002^{\star}$
\end{tabular}

Note: Data expressed as median (minimum - maximum, MannWhitney $U$ test for independent samples, * significant values considering $p<0.05$. Source: Research data, 2017.

Table 3 shows the association between the patients' sedation level and their clinical outcome, where $66 \%$ exhibited a sedation level between -4 and -5 died. By contrast, $71.4 \%$ of patients with a sedation level between -1 and 0 were discharged from the unit, meaning that more patients in the study sample died with a higher sedation level, with Fisher's Exact Test demonstrating a significant difference $(\mathrm{p}=0.011)$. 
Table 3 - Association between RASS and the patients' clinical outcome

\begin{tabular}{lccc} 
& \multirow{2}{*}{ RASS } & \multicolumn{3}{c}{ Outcome } \\
\cline { 2 - 4 } & Death (n\%) & Discharged (n\%) & Total (n\%) \\
\hline-5 E -4 & $8(66.7)$ & $4(19.0)$ & $12(36.4)$ \\
-3 E -2 & $1(8.3)$ & $2(9.5)$ & $3(9.1)$ \\
-1 E 0 & $3(25.0)$ & $15(71.4)$ & $18(54.5)$ \\
Total & $12(100.0)$ & $21(100.0)$ & $33(100.0)$ \\
\hline
\end{tabular}

Note: $\mathrm{n}$ : Absolute frequency, \%: Relative frequency, Fisher's Exact Test : 7.633, p-value of Fisher's test: 0.011; Cramer's V: 0.486; $p$-value of Cramer's V: 0.015. Source: Research data, 2017.

As one of the main barriers identified, the use of mechanical ventilation was associated with the Perme Score and low scores on the scale $(\mathrm{p}=0.000)$ (Table 4).

The results obtained showed a moderate positive correlation $(\mathrm{R}=0.745)$ between the total Perme Score and sedation level measured by RASS, indicating that the more awake the patient the higher the Perme Score. A moderate inverse correlation was found between APACHE and the Perme Score ( $\mathrm{R}=-0.526)$ and APACHE and days on invasive mechanical ventilation $(R=-0.602)$ (Table 5).

Table 4 - Association between invasive mechanical ventilation and the Perme Score

\begin{tabular}{|c|c|c|c|c|}
\hline \multirow{2}{*}{ Use of IVM } & \multicolumn{3}{|c|}{ Perme Score } & \multirow[b]{2}{*}{$\mathrm{p}$-value } \\
\hline & $n$ & Mean & SD & \\
\hline Yes & 20 & 2.40 & 4.19 & 0.000 * \\
\hline No & 13 & 12.85 & 6.61 & \\
\hline
\end{tabular}

Note: IVM: Invasive mechanical ventilation; $\mathrm{n}=$ Absolute frequency; $\mathrm{SD}=$ Standard deviation; * significant for the Student's t-test for independent samples, $p<0.0$. Source: Research data, 2017.

Table 5 - Correlation between sedation level, patient severity and days on invasive mechanical ventilation and the Perme Score

\begin{tabular}{lccc} 
& Variables & & Perme Score \\
& $\mathbf{n}$ & $\mathbf{R}(\mathbf{p})$ \\
\cline { 2 - 3 } RASS & 33 & $0.745^{\star *}(0.00)$ \\
\hline APACHE & 33 & $-0.526(0.002)$ \\
Days on IVM & 33 & $-0.602^{\star *}(0.000)$ \\
\hline
\end{tabular}

Note: R: Pearson's correlation, ${ }^{\star \star}$ significant value for $p<0.01$. Source: Research data, 2017.

\section{Discussion}

The Perme Score is a new tool used as an assessment criterion in intensive care units. This study aimed to determine whether mobility, the main aspect assessed by this scale, would have a relationship or not with the outcome of patients in a particular ICU. In addition to showing a relationship with outcome, it was also strongly correlated with sedation level and patient severity.
In terms of diagnosis, the sample characteristics are similar to those of another study that investigated clinical causes, underscoring digestive and pulmonary disorders. It is believed that this finding in terms of digestive causes is due to the fact that the hospital where the study was conducted provides a considerable number of surgical services in this area [20]. 
The results of the present study stand out particularly for the low patient mobility and the fact that the low scores on the Perme Score domains of mental status, barriers to mobility, strength and mobility in bed, as well as the overall score were significantly associated with the death outcomes. This suggests that the poor functional mobility of the study sample is strongly associated with the mortality of these individuals.

Studies show that in patients whose health status is critically compromised, muscle atrophy is even more significant as a consequence of prolonged bed rest, causing an important reduction in muscle activity $[21,22]$.

Considering this aspect, restricted or reduced mobility is a precursor condition of functional decline, and an integral part of the components that contribute to the emergence of myopathy and polyneuromyopathy of the critical disease, which is exacerbated by the nutritional status of a majority of the individuals affected, due to inflammatory muscle catabolism [21,23].

The acquired weakness and functional deficits caused by the critical disease mentioned earlier seem to be closely related to the reduced transfer ability observed here, especially related to gait and endurance.

It is important to underscore that the study participants required almost total assistance to perform transfers and maintain posture, which also influences the ability to walk. This could explain why most patients obtained low transfer, gait and endurance Perne scores and no association between these variables and the clinical outcome.

As previously mentioned, the worst Penne scores were related to transfer, gait and endurance. A study conducted in public ICUs showed that out-of-bed mobilization such as static gait and walking are still performed in fewer than $50 \%$ of ICU patients. This is usually related to the instability and severity of the patients themselves [24].

However, another study demonstrated the lack of understanding of mobilization as one of the main priorities in ICUs, as well as disagreements between the teams and insecurity regarding the mobilization of the most critical patients, especially those on mechanical ventilation [25].

The environment and physical space, as well as monitoring in the ICU cause limitations that often compromise the possibility or quality of early mobilization. The use of artificial airways, sedation, femoral catheter insertion, and renal replacement therapy are commonly observed, in addition to cultural barriers, underscoring interaction difficulties in the multidisciplinary team [26].
A prospective study carried out in an intensive care facility reaffirmed that the barriers to mobility identified were totally modifiable, highlighting femoral catheters, bedside procedure time and sedation. This suggests that simple measures such as better drug management, as well as the selection of the vascular device insertion site contributed to better patient mobilization [27].

Given the functional impairments acquired during the critical disease, a binational multicenter study investigated the current practice of early mobilization in an ICU, demonstrating that a significant portion of the population did not receive any type of mobilization, especially in patients on mechanical ventilation, with sedation and mechanical ventilation as the primary barriers identified [20].

Thus, as described by the previously mentioned authors, this study highlighted the use of mechanical ventilation and access to vasoactive drug infusion and sedation in a large part of the population studied.

Early mobilization is strongly encouraged due to benefits such as improved functional independence and quality of life after ICU discharge [28]. However, a multicenter study in Brazil showed that the prevalence of patient mobilization in the ICU, especially those on mechanical ventilation, is still very low (2\%), with weakness, cardiovascular instability and sedation as the main barriers identified [29].

Another recent prevalence study investigated 26 Brazilian ICUs and showed that $87.4 \%$ of the population underwent some type of mobilization. However, passive activities restricted to the bed predominated, particularly in patients on mechanical ventilation [30].

It can therefore be inferred that alertness, the ability to respond to stimuli and the patient's environment may facilitate or limit mobilization, thereby compromising mobility. The presence of the barriers identified in this study explains the intrinsic association between the low Perme Score and the use of mechanical ventilation.

Studies report that functional impairments and the cognitive status of critical patients are exacerbated by how sedation levels are managed, mechanical ventilation is monitored and patients are mobilized, and given that functional condition and neurological status are affected by disease, they can worsen according to the approach used, whether pharmacological or not $[22,31,32]$.

Considering sedation as a possible barrier to mobility, the sedation level showed that the RASS between -4 and -5 on the second day after admission obtained in the present study demonstrated a greater 
association with death outcomes. By contrast, the main outcome for those with sedation levels between -1 and 0 was ICU discharge.

Corroborating these results, a recent study found that after tracheal intubation, deeply sedated patients who obtained a RASS between -3 and -4 in the first $24 \mathrm{~h}$, and -3 and -1 in the first $48 \mathrm{~h}$ performed worse, making it possible to associate the higher sedation level with greater mortality in the population under study [19].

Given the severity and vulnerability of patients hospitalized in the ICU, the search for prognostic factors is increasingly necessary, in addition to guiding strategies and enabling an adequate approach to the patient. APACHE II is an important scale for predicting the risk of mortality by assessing acute clinical data and the chronic aspects of patients [33,34].

Despite the unfavorable contribution that functional decline and low mobility seem to have on patient outcomes, APACHE II does not assess these components. In the present study, the average APACHE II score was 22.8 points, reflecting the severe state of the individuals assessed, confirmed by the total mortality percentage, given that more than $36 \%$ of the sample evolved to death in the ICU.

Similar results were observed in a study that performed a comparative analysis of mortality prediction scores and found that the patients who died obtained APACHE II scores of more than 20 points, which is in line with the data of the present research $[33,35]$.

In a study that investigated the relationship between previous functional status of critically ill individuals and mortality predicted by APACHE II, it was found that the functional situation significantly influences the outcome of patients admitted to the ICU, demonstrating the relevance of assessing this component in conjunction with mortality prediction scores, pre-admission functional independence and APACHE II [36].

As such, based on the findings of the present study, in addition to prior functional status, the mobility score may be an important clinical assessment factor in patient admission given the moderate relationship between the Perme Score and APACHE II, in addition to the statistically significant results and clinical outcome.

Despite the evidence of the the benefits of mobilization, questions arise on why it continues to be infrequently applied in the ICU. Among the hypotheses are the organizational aspects of the units and the need for cooperation from the medical team, which are indispensable to the process. It is important to underscore that implementing initiatives to overcome the barriers to mobilization is a factor that still limits adherence by the multiprofessional team, highlighting the difference between evidence-based recommendations and what actually occurs in the ICU in terms of early mobilization $[37,38]$.

Including patient mobilization as a routine is a challenge that requires cultural changes and the integrated participation of ICU professionals, in addition to implementing viable scales and scoring systems that can guide objectives and show the barriers that need to be overcome [39].

\section{Study limitations}

This study exhibits limitations such as sample size and data collection duration. It is important to underscore that it was carried out at a single location, suggesting the need for further investigations with larger populations, longer collection times and other variables.

\section{Conclusion}

In the present study, there was a relationship between the clinical outcome of patients and mobility scores, where low Perme and high APACHE II scores were associated with death outcomes. The potential barriers to mobility include the use of mechanical ventilation and access to continuous infusion and sedation, where the highest sedation levels were associated with low mobility and higher mortality.

Thus, poor mobility at admission was an important finding that was directly related to death outcomes, and avoidable barriers may have contributed to the low mobilization and poor outcome in the patients studied.

\section{References}

1. Parry SM, Denehy L, Beach LJ, Berney S, Williamson HC, Granger CL. Functional outcomes in ICU - what should we be using? - an observational study. Crit Care. 2015;29;19(1):127. 
2. Santos LJ, Silveira FS, Müller FF , Araújo HD , Comerlato BJ , Silva MC, et al. Avaliação funcional de pacientes internados na Unidade de Terapia Intensiva adulto do Hospital Universitário de Canoas. Fisioter Pesqui. 2017;24(4):437-43.

3. Singer P. Preserving the quality of life: Nutrition in the ICU. Crit Care. 2019;23(Suppl 1):1-5.

4. Curzel J, Forgiarini Jr LA, Rieder MM. Evaluation of functional independence after discharge from the intensive care unit. Rev Bras Ter Intensiva. 2013;25(2):93-8.

5. Richard D, Zorowitz MD. ICU-Acquired weakness a rehabilitation perspective of diagnosis, treatment, and functional management. CHEST. 2016;150(4):966-71.

6. Zhang L, Hu W, Cai Z, Liu J, Wu J, Deng Y, et al. Early mobilization of critically ill patients in the intensive care unit: A systematic review and meta-analysis. PLoS One. 2019;14(10):1-16.

7. Jesus FS, Paim DM, Britoj O, Barros IA, Nogueira TB, Martinez BP, et al. Mobility decline in patients hospitalized in an intensive care unit. Rev Bras Ter Intensiva. 2016;28(2):114-9.

8. Paiva DN, Bordin DF, GASS R, Severo RJ, Brum NR, Niedermeyer CC. Avaliação da força de preensão palmar e dos volumes pulmonares de pacientes hospitalizados por condições não cirúrgicas. Sci Med (Porto Alegre). 2014;24(1):61-7.

9. Machado AS, Pires-Neto RC, Carvalho MTX, Soares JC, Cardoso D M. Effects that passive cycling exercise have on muscle strength, duration of mechanical ventilation, and length of hospital stay in critically ill patients: a randomized clinical trial. J Bras Pneumol. 2017;43(2):134-9.

10. Murakami FM, Yamaguti WP, Onoue MO, Mendes JM, Pedrosa RS, Maida ALM, et al. Evolução funcional de pacientes graves submetidos a um protocolo de reabilitação precoce. Rev Bras Ter Intensiva. 2015;27(2):161-9.

11. Hopkins RO, Mitchell L, Thomsen GE, Schafer M, Link M, Brown SM. Implementing a Mobility Program to Minimize Post-Intensive Care Syndrome. AACN Adv Crit Care. 2016;27(2):187-203.
12. Parry SM, Huang M, Needham DM. Evaluating physical functioning in critical care: considerations for clinical practice and research. Crit Care. 2017;21:249.

13. Seguel FG, Corner EJ, Osorio CM. International Classification of Functioning, Disability, and Health Domains of 60 physical functioningmeasurement instruments used during the adult intensive care unit stay: a scoping review. Phys Ther. 2016;99(5):627-40.

14. Sommers J, Vredeveld T, Lindeboom R, Nollet F, Engelbert $\mathrm{RHH}$, Schaaf MV, et al. The Morton Mobility index is feasible, reliable, and valid in patients with critical illness. Phys Ther. 2016;96(10):1-9.

15. Kawaguchi YMF, Nawa RK, Figueiredo TB, Martins L, Pires-Neto RC. Perme Intensive Care Unit Mobility Score and ICU Mobility Scale: translation into Portuguese and cross-cultural adaptation for use in Brazil . J Bras Pneumol. 2016;42(6):429-34.

16. Perme CPT, Nawa RK, Winkelman C, Masud F. A Tool to Assess Mobility Status in Critically Ill Patients: The Perme Intensive Care Unit Mobility Score. Methodist Debakey Cardiovasc J. 2014;10(1):41-9.

17. Pereira CS , Carvalho AT , Bosco AD , Forgiarini Jr LA. The Perme scale score as a predictor of functional status and complications after discharge from the intensive care unit in patients undergoing liver transplantation. Rev Bras Ter Intensiva. 2019;31(1):57-62.

18. Marcela Libuy MH, Szita PC, Hermosilla JP, Arellano DS, Núñez IR, Báez CR. Validez y confiabilidad de las escalas de evaluación funcional en pacientes criticamente enfermos. Revisión sistemática. Rev Med Chile. 2017;145(9):1137-44.

19. Stephens RJ, Ablordeppey E, Drewry AM, Palmer C, Wessman BT, Mohr NM. Analgosedation practices and the impact of sedation depth on clinical outcomes among patients requiring mechanical ventilation in the ED: A cohort study. Chest. 2017;152(5):963-71.

20. Needham DM, Davidson J, Cohen H, Hopkins RO, Weinert C, Wunsch $\mathrm{H}$, et al. Early mobilization and recovery in mechanically ventilated patients in the ICU: a binational, multi-centre, prospective cohort study. Crit Care. 2015;19(81):1-10.

21. Zorowitz RD. Rehabilitation perspective of diagnosis, treatment, and functional management. Chest. 2016;150(4):966-71. 
22. Jolley SE, Bunnell AE, Hough CL. ICU-Acquired Weakness. Chest. 2016;150(5):1129-40.

23. Bear DE, Wandrag L, Merriweather JL, Connolly B, Hart NT, Grocott MPW. The role of nutritional support in the physical and functional recovery of critically ill patients: a narrative review. Criti Care. 2017;21(1):226.

24. Tadyanemhandu C, van Aswegen H, Ntsiea V. Organizational structures and early mobilization practices in South African public sector intensive care units - A cross-sectional study. J Eval Clin Pract. 2020:1-11

25. Anekwe DE, Koo KKY, Marchie M, Goldberg P, Jayaraman D, Spahija J. Interprofessional survey of perceived barriers and facilitators to early mobilization of critically ill patients in Montreal, Canada. J Intensive Care Med. 2019;34(3):218-26.

26. Hashem MD, Parker AM, Needham DM. Early mobilization and rehabilitation of patients who are critically ill. Chest. 2016;150(3):722-31.

27. Fontela PC, Lisboa TC, Forgiarini-Júnior LA, Friedman G. Early mobilization practices of mechanically ventilated patients: a 1-day point-prevalence study in southern Brazil. Clinics. 2018;73:e241.

28. Watanabe S, Kotani T, Taito S, Ota K, Ishii K, Ono M, et al. Determinants of gait independence after mechanical ventilation in the intensive care unit: A Japanese multicenter retrospective exploratory cohort study. J Intensive Care. 2019;7(1):1-9

29. Hodgson CL, Capell E, Tipping CJ. Early Mobilization of Patients in Intensive Care: Organization, Communication and Safety Factors that Influence. Critical Care. 2018;22(1)77.

30. Timenetsky KT, Serpa Neto A, Assunção MSC, Taniguchi L, Eid RAC, Corrêa TD. Mobilization practices in the ICU: A nationwide 1-day point- prevalence study in Brazil. PLoS One. 2020;15(4): e0230971.
31. Andharipande PP, Girard TD, Jackson JC, Morandi A, Thompson JL, Pun BT, et al. Long-Term Cognitive Impairment after Critical Illness. N Engl J Med. 2013;369(14):1306-16.

32. Vincent JL. The continuum of critical care. Crit Care. 2019;23(Suppl 1):19-23.

33. Keegan MT, Soares M. O que todo intensivista deveria saber sobre os sistemas de escore prognóstico e mortalidade ajustada ao risco. Rev Bras Ter Intensiva. 2016;28(3):264-9

34. Basile-Filho A, Lago AF, Menegheti MG, Nicolini EA, Rodrigues LAB, Nunes RS, et al. The use of APACHE II, SOFA, SAPS 3, C-reactive protein/albumin ratio, and lactate to predict mortality of surgical critically ill patients: A retrospective cohort study. Medicine (Baltimore). 2019;98(26):e16204.

35. Hissa PNG, Hissa MRN, Araújo PSR. Análise comparativa entre dois escores na previsão de mortalidade em unidade terapia intensiva. Rev Bras Clin Med. 2013;11(1):21-6.

36. Krinsley JS,Wasser T, Kang G, Bagshaw SM. Preadmission functional status impacts the performance of the APACHE IV model of mortality prediction in critically ill patients. Critical Care. 2017;21(1):110.

37. Honiden S, Connors GR. Barriers and challenges to the successful implementation of an intensive care unit mobility program understanding systems and human factors in search for practical solutions. Clin Chest Med. 2015;36(3):431-40.

38. Fontela PC, Forgiarini Jr LA, Friedman G. Clinical attitudes and perceived barriers to early mobilization of critically ill patients in adult intensive care units. Rev Bras Ter Intensiva. 2018;30(2):187-94.

39. FuestK, Schaller SJ. Recent evidence on early mobilization in critical-Ill patients. Curr Opin Anaesthesiol. 2018;31(2):144-50.
Received: 05/26/2019

Recebido: 26/05/2019

Approved: 08/03/2020

Aprovado: 03/08/2020 